\title{
Ciências da Natureza e materialismo histórico-dialético: encontros e desencontros na formação de educadores do campo
}

\author{
Emilio Romanini Netto ${ }^{1}$ \\ ${ }^{1}$ Universidade Federal do Paraná - UFPR. Setor de Ciências Agrárias. Rua dos Funcionários, 1540. Curitiba - PR. Brasil. \\ Autor para correspondência/Author for correspondence: emilioromanini@hotmail.com
}

\begin{abstract}
RESUMO. A temática deste artigo é produto da investigação realizada para monografia de especialização realizada pelo autor, onde, exploramos a relação particular dos movimentos sociais populares do campo (MSPdoC) com dois campos de estudo: a Educação do Campo e a Agroecologia. Aqui procuramos compreender a adoção do materialismo históricodialético na concepção originária de Educação do Campo dos MSPdoC como um fenômeno a parte. O fizemos com apoio da Sociologia do Conhecimento e da Filosofia e História da Ciência. Assim, o objetivo deste artigo é identificar encontros e desencontros do enlace entre a Ciências da Natureza e o materialismo histórico-dialético, ao relacionar com o projeto de formação de educadores do campo. Foi possível entender que o materialismo histórico-dialético é capaz de fundamentar novas análises sobre a realidade natural. Contudo, a disputa de concepção entre os sujeitos envolvidos na execução do projeto de Educação do Campo e os formatos disciplinares dos cursos de Pedagogia e Licenciatura nos aparece como desencontros. Outro desencontro se refere aos conteúdos dos materiais didáticos das Ciências da Natureza não convergirem a uma perspectiva co-evolutiva ou histórico-natural. O nosso trabalho encontra um horizonte possível, o princípio educativo do trabalho, tanto para o processo educativo quanto para o científico.
\end{abstract}

Palavras-chave: Educação do Campo, Ciências da Natureza, Filosofia da Ciência.

\begin{tabular}{|l|l|l|l|l|l|l|l|}
\hline Rev. Bras. Educ. Camp. & Tocantinópolis & v. 3 & n. 3 & p. 1009-1036 & set./dez. & 2018 & ISSN: 2525-4863 \\
\hline
\end{tabular}




\title{
Natural Sciences and historical-dialectical materialism: meetings and disagreements in formation of rural teachers
}

\begin{abstract}
The theme of this article results of the research to the specialization monography conducted by the author, where we explored the particular relationship of the popular rural social movements (MSPdoC) with two fields of study in particular: Rural Education and Agroecology. Here we seek to understand the adoption of historical-dialectical materialism in the original conception of Rural Education of the MSPdoC as a phenomenon aside, worthy of reflection. We did so with the support of Sociology of Knowledge and Philosophy and History of Science. Thus, the aim of this article is to identify meetings and disagreements between the Natural Sciences and historicaldialectical materialism, as it relates to the education of rural teachers. It was possible to understand that historical-dialectical materialism is capable of substantiating new analyzes of natural reality. However, the conception dispute between the subjects involved in the implementation of the Rural Education project and the disciplinary formats of the Pedagogy and Graduation courses appear to us as disagreement. Another disagreement refers to the contents of didactic materials of the Natural Sciences do not converge to a co-evolutionary or historicalnatural perspective. Our work finds to a possible horizon, the educational principle of work, both for the educational process and for the scientific.
\end{abstract}

Keywords: Rural Education, Natural Sciences, Philosophy of Science. 


\section{Ciencias de la Naturaleza y materialismo histórico- dialéctico: encuentros y desencuentros en la formación de educadores del campo}

RESUMEN. La temática de este artículo es producto de la investigación para monografía de especialización realizada por el autor, donde exploramos la relación particular de los movimientos sociales populares del campo (MSPdoC) con dos campos de estudio en especial: la Educación del Campo y la agroecología. Aquí tratamos de comprender la adopción del materialismo histórico-dialéctico en la concepción originaria de Educación del Campo de los MSPdoC como un fenómeno aparte, digno de reflexión. Lo hicimos con apoyo de la Sociología del Conocimiento y de la Filosofía y Historia de la Ciencia. Así, el objetivo de este artículo es identificar encuentros y desencuentros del enlace entre las Ciencias de la Naturaleza y el materialismo histórico-dialéctico, al relacionarse con el proyecto de formación de educadores del campo. Es posible entender que el materialismo histórico-dialéctico es capaz de fundamentar nuevos análisis sobre la realidad natural. Sin embargo, la disputa de concepción entre los sujetos involucrados en la ejecución del proyecto de Educación del Campo y los formatos disciplinarios de los cursos de Pedagogía y Licenciatura nos aparece como desencuentros. Otro desencuentro se refiere a los contenidos de los materiales didácticos de las Ciencias de la Naturaleza no convergen a una perspectiva co-evolutiva o histórica-natural. Nuestro trabajo encuentra un horizonte posible, el principio educativo del trabajo, tanto para el proceso educativo y para el científico.

Palabras clave: Educación del Campo, Ciencias de la Naturaleza, Filosofía de la Ciencia. 


\section{Introdução}

A temática deste artigo é produto da monografia de especialização realizada pelo autor, onde, foi possível distinguir a relação particular dos movimentos sociais populares do campo (MSPdoC) com dois campos de estudo em especial: a Educação do Campo e a agroecologia. A pesquisa foi realizada durante o período em que autor compôs o Coletivo Político-Pedagógico da Escola Latino-Americana de Agroecologia (ELAA - Via Campesina) durante a execução da Licenciatura em Educação do Campo - Ciências da Natureza (LECAMPO) em parceria com a Universidade Federal do Paraná (UFPR/ Litoral). Durante o processo de pesquisa de campo e revisão bibliográfica foi possível abstrair a concepção originária de Educação do Campo derivada dos movimentos sociais. Afirmamos que a concepção de educação praticada nos centros de formação dos MSPdoC tem forte influência da Educação Popular, principalmente a pedagogia de Paulo Freire; da Pedagogia Socialista, com centralidade nos pedagogos russos como Pistrak, Makarenko, Shulgin; e da Pedagogia do Movimento. Existe uma relação, mais ou menos íntima, entre estes pilares teóricos com a teoria de Marx e
Engels, mais especificamente o desenvolvimento do método materialista histórico-dialético.

Se a Educação do Campo nasceu das lutas, pressões e mobilizações dos MSPdoC organizados, em sua trajetória é adicionado ao seu movimento real a condição de legalidade. Em meio ao acirramento das lutas no campo no final dos anos 1990, o estado se viu pressionado pelos MSPdoC e, por fim, cedeu lançando o primeiro Programa Nacional de Educação na Reforma Agrária (PRONERA), em 1998, e se torna política pública com o Programa Nacional de Educação do Campo (PRONACAMPO) em 2010.

Os livros Caminnhos para a transformação da escola vol 1 e 2, publicados pela Expressão Popular, são produtos da experiência dos centros de formação dos movimentos sociais com os cursos do PRONERA e PROCAMPO. Tais materiais sugerem em diferentes momentos a importância de se levar em conta o método materialista histórico-dialético na leitura da realidade, assim como método científico, explorando suas categorias como alternativa ao projeto de educação hegemônico, com intuito de superar a fragmentação dos objetivos escolares, da própria produção científica, conectando a prática do ensino à realidade do campo, e 
priorizando, enfim, a construção de uma sociedade sem a submissão de uma classe social $^{1}$ à outra. (Caldart, 2010; Rodrigues, 2010; Iejc, 2015; Rolo, 2015).

Em particular, o texto síntese do Seminário sobre o Ensino de Ciências da Natureza nas Escolas do Campo (Instituto de Educação Josué de Castro [IEJC], 2015) nos traz o materialismo histórico-dialético como meio para reconhecer o trabalho como princípio educativo, e no trabalho a categoria principal de relação homemnatureza, como meio para superação da concepção positivista e mecanicista de natureza. Contudo, a utilização do método materialista histórico-dialético na produção e ensino das Ciências Naturais não se dá $a$ priori. De fato é uma temática polêmica à intelectuais com posições divergentes. $\mathrm{O}$ método elaborado por Marx e Engels, se desenvolveu, a rigor, no campo da Economia Política com intuito de apreender a totalidade da sociedade burguesa. Com isso, a aplicação do método para compreensão da realidade natural é sujeita à crítica de intelectuais divergentes ao marxismo, assim como de marxistas.

Segundo Foster (2005), os intelectuais que deram continuidade ao pensamento de Marx se distanciaram das Ciências Naturais, criando um vácuo na produção teórica, que se agravou com os críticos do materialismo. No desenvolvimento do marxismo, o materialismo (dos marxistas) teria se tornado cada vez mais "abstrato e a rigor sem sentido, reduzido na última instância da produção da vida, a da existência econômica, sobre elementos 'superestruturais', tais como as ideias" (Foster, 2005, p. 22). Para Lopes (1999) a derrocada da epistemologia marxista no campo das Ciências da Natureza se dá no período stalinista da União Soviética, sob o comando de Lyssenko. Não obstante, os comunistas e o movimento operário geralmente são criticados por manterem uma visão utilitarista em relação à natureza, onde o materialismo marxista é reconhecido por manter a mesma visão de dominação do materialismo mecanicista. Em outras palavras, para Giddens (1996) "o marxismo e o socialismo, de maneira mais genérica, são cúmplices da ordem social que afirmam atacar".

Neste bojo teórico, este artigo procura compreender a adoção do materialismo histórico-dialético na concepção originária de Educação do Campo dos MSPdoC como um fenômeno a parte, digno de reflexão. E o será feito com apoio da Sociologia do Conhecimento e da Filosofia e História da Ciência. Contudo, o objetivo deste artigo é identificar encontros e desencontros do enlace entre a Ciências da Natureza e o materialismo histórico- 
dialético, ao relacionar com os desafios do projeto de formação de educadores do campo.

Começaremos expondo a construção do projeto de educação, segundo nossa pesquisa, de acordo com a perspectiva dos MSPdoC, levando em consideração gênese, lutas sociais e definição teóricoprática.

\section{A necessidade de transformação da escola}

Os MSPdoC possuem uma íntima relação com a educação, poderíamos dizer embrionária. O processo de organização dos sujeitos marginalizados pelo avanço da colonização e expansão da agricultura latifundiária esteve intimamente ligado à proposta de Educação Popular promovida especialmente por setores da Igreja Católica, a partir dos anos 1960. Neste período aflorava dentro dos setores cristãos uma atração pelo marxismo com o surgimento de uma corrente interna chamada Teologia da Libertação. Segundo Lowy (2007) a Teologia da Libertação não criou essa mudança, é produto dela. Seu reflexo prático se traduzia em um maior envolvimento de cristãos em associações de bairro, sindicatos, movimentos estudantis, ligas camponesas, centros de Educação Popular, partidos políticos de esquerda e organizações revolucionárias. $\mathrm{O}$ avanço de atuação Comunidades Eclesiais de Base (CEB's), dos Centros de Educação Popular e as Pastorais da Terra tiveram forte influência na organização popular no campo e que foram os motores do surgimento dos MSPdoC, como o Movimento dos Trabalhadores Rurais Sem Terra (MST), Movimento dos Atingidos por Barragens (MAB), Conselho Indigenísta Missionário (CIMI), Movimento dos Pequenos Agricultores (MPA), Movimento das Mulheres Camponesas (MMC), ente outros.

O crescente número de ocupações de terra no final da década de 1970 pelos sujeitos que viriam a se organizar no MST afrontava a classe agrária dominante, as oligarquias e o poder público. E com os acampamentos surgia uma nova questão: crianças acampadas, o que fazer com elas?

$\mathrm{O}$ texto que conta o ponto inicial deste momento chama-se Nossa luta é nossa escola (Movimento dos Trabalhadores Rurais Sem Terra [MST], 2005). Neste momento histórico inicia-se a luta pelo direito de educação na reforma agrária, e esta luta, desde sua origem, não se restringia ao acesso à escola. $\mathrm{O}$ debate principal estava em como materializar uma construção alternativa de escola, centrada não somente na relação entre educação e produção, mas que inserisse a escola na construção dos assentamentos que 
começavam a ser conquistados. Neste período (anos noventa) se consolidava o Setor de Educação do MST.

O desafio de praticar um modelo diferente de educação levou ao Setor de Educação a manter-se produzindo materiais que ajudassem no processo de formação dos militantes assim como de reflexão, unindo as teorias pedagógicas ao projeto formativo de um novo sujeito. A primeira produção de caráter políticopedagógico feita em colaboração entre o Setor de Educação e o Setor de Formação é o texto $O$ que queremos com as escolas dos assentamentos publicado em 1991 (MST, 1999), produto de pelo menos dez anos de práticas de educadores, educandos, pais e lideranças dos assentamentos e acampamentos que constituíram o MST. Em linhas gerais, o texto antecede alguns princípios os quais iriam se manter na essência da proposta de Educação do Campo.

A construção deste acúmulo culminou em 1997 com o I Encontro Nacional das Educadoras e Educadores da Reforma Agrária (I ENERA) realizado em Luziânia-GO resultado da parceria do Setor de Educação do MST juntamente ao Grupo de Trabalho de Apoio à Reforma Agrária da Universidade de Brasília, Fundo das Nações Unidas para Infância (UNICEF), Organização das Nações
Unidas para a Educação, a Ciência e a Cultura (UNESCO) e Conferência Nacional dos Bispos do Brasil (CNBB). Estiveram presentes no I ENERA professores de mais de vinte universidades, educadoras e educadores de áreas de reforma agrária de diversas regiões do país além de amigos do MST. Neste evento tornaram-se evidentes os principais problemas: o grande número de analfabetos em áreas de reforma agrária e a necessidade de uma política pública específica (Ministério do Desenvolvimento Agrário [MDA], 2004).

Ao final do I ENERA, em meio ao entusiasmo de seu êxito, as entidades promotoras e as que apoiaram o evento foram desafiadas para um trabalho mais amplo sobre educação a partir do mundo rural. Os representantes das entidades aceitaram a tarefa e ainda em 1997 escolheram o nome Conferência por uma Educação Básica do Campo, realizado em 1998. Desde o início chegou-se ao consenso específico da "educação básica do campo" que levasse em conta a cultura, as características, as necessidades e os sonhos dos que vivem no campo e do campo. Outro consenso entre os promotores era sua vinculação com um projeto popular de Brasil e com um projeto popular de desenvolvimento do campo. Após a realização da conferência as cinco 
entidades promotoras assumiram $\mathbf{O}$ compromisso de dar continuidade à mobilização "Por uma Educação Básica do Campo", assim se estabeleceu então uma articulação nacional e um fórum nacional (Kolling, Nery \& Molina, 1999).

O ano de 1998 também é um marco ao movimento da Educação do Campo, seu início como política pública. A criação do PRONERA abriu portas para aumentar o alcance da educação formal nas áreas de reforma agrária, sobretudo com o apoio do movimento Por uma Educação do Campo ganhou contextos mais abrangentes. À medida que os MSPdoC foram acumulando posicionamentos claros em relação a construção de uma nova proposta de escola logo se concluiu a necessidade de uma nova proposta de formação dos educadores. Não adiantava recriar o ambiente escolar se os educadores não estivessem preparados para promover uma nova proposta de educação. Neste contexto torna-se tático para os MSPdoC a disputa no ensino superior. As primeiras experiências se deram após a II Conferência Nacional em Educação do Campo, no ano de 2004. Foram iniciadas as Pedagogias da Terra, apoiadas pelo PRONERA e em 2006 temos a criação do Programa de Apoio às Licenciaturas em Educação do Campo (PROCAMPO).
Mas que formação de educadores deve ser essa para dar conta de transformar a escola? O professor Miguel Arroyo nos ajuda a entender que em primeiro lugar deve-se superar um protótipo único de docente-educador. Ou seja, que todo professor deve estar capacitado para desenvolver os mesmos saberes e competências independentes da diversidade de coletivos humanos. Sem a superação desse protótipo único persiste a formação que privilegia a visão urbana, vê os povos/escolas do campo como minorias e privilegia a contratação de professores das cidades sem vínculo com a escola do campo. (Arroyo, 2012, p. 359).

Neste sentido, Caldart (2010, p.132) desenvolve três conjuntos de aprendizados básicos de formação para os educandos do campo, futuros educadores: a) docência multidisciplinar em uma das áreas de conhecimento; b) gestão de processos educativos escolares, para a construção do projeto político-pedagógico e para organização do trabalho escolar e pedagógico nas escolas do campo; c) atuação pedagógica nas comunidades rurais, para a liderança de equipes e para implementação de projetos de desenvolvimento comunitário sustentável. Exploraremos estes elementos.

A docência multidisciplinar quer dizer um momento de tensão da prática 
docente, qual seja, o trabalho em equipe, a possibilidade de quebrar a individualidade que cada docente assume ao se responsabilizar por somente uma disciplina e reivindicar sua autonomia desde então. Para Caldart (2010) este exercício visa objetivos importantes. Em primeiro lugar é o de promover espaço para o trabalho coletivo dos educadores, central para o rompimento na fragmentação curricular e para o estudo da realidade da vida camponesa. Em segundo lugar resguardar a especificidade das áreas do conhecimento na compreensão da realidade e aø trazer os elementos da prática social dos educandos para a sala de aula e os relacionar. No que diz respeito à gestão, é importante que o novo educador esteja preparado para compreender a gestão escolar em sua totalidade para que este sujeito seja capaz de adequar o projeto formativo a cada etapa e modalidade da Educação Básica. Ao que se refere à atuação pedagógica nas comunidades relacionamos aqui, não só o que se refere à prática docente inserida na realidade, mas também como o processo educativo, seja na formação de educadores seja no ensino básico. É o que Caldart (2010) chama atenção para uma visão alargada de educação, ou seja, "assumir uma visão que vincula a educação a processos de formação do ser humano, que podem acontecer com intencionalidade pedagógica em diferentes lugares sociais, diferentes situações ... que implicam um mesmo desafio que é o de transformação do ser humano" ( p. 135).

Neste sentido, um dos principais desafios, ressalta Caldart (2010), é o de fazer do campo um objeto central de estudo sistemático e rigoroso do curso. Este desafio exigiria estudar como as contradições do modo de produção capitalista se desenvolvem no campo, para que seja capaz de formular sínteses que permitam identificar os diferentes projetos de campo/território em disputa no Brasil, e principalmente tomar posição para desenvolver seu trabalho educativo considerando as lutas sociais no campo. Este desafio, também, está atrelado a conhecer e reconhecer a lógica da produção e reprodução da vida camponesa, não apenas como resistência, mas como projeto de outro modo de produção possível, que inclui uma nova relação social e com a natureza. Aqui o foco não é apenas garantir momentos de contextualização dos conteúdos, mas sim juntar teoria e prática. A diferença fundamental acontece a partir da concepção de uma educação omnilateral, em que a educação integra um projeto de formação humana para a transformação da sociedade desde a perspectiva teórica e 
política do materialismo histórico-dialético no trabalho pedagógico escolar.

Uma opção possível é o princípio educativo do trabalho. Dentro da perspectiva marxista a categoria trabalho é central à análise do modo de produção e das relações sociais. $\mathrm{Na}$ análise históricocrítica de Saviani (2007) o trabalho e a educação são atividades especificamente humanas. A categoria do trabalho engloba as atividades humanas que transformam a natureza a fim de prover a produção da vida. Para Saviani, "no entanto, o homem não nasce sabendo produzir-se como homem. Precisa aprender a produzir sua própria existência. Portanto a produção do homem é, ao mesmo tempo, a formação do homem, isto é, um processo educativo" (Saviani, 2007, p. 154). No entendimento de Oliveira e Goméz (2014), pensar o trabalho como princípio educativo significa estar sob uma racionalidade e uma normatividade, implícitos em processos sociais, onde o trabalho é capaz de educar, de desenvolver o homem em todas suas potencialidades.

Os estudos do professor Luiz Carlos de Freitas sobre a Pedagogia Socialista desenvolvida na União Soviética entre os anos de 1917 e 1930 vem sendo um motivador de uma educação voltada a reparar sua separação com o trabalho. Para Freitas (2010) "ter o trabalho como princípio educativo é mais do que ligar a educação com o trabalho produtivo de bens e serviços. Tomar o trabalho como princípio educativo é tomar a própria vida (atividade humana criativa) como princípio educativo" (p. 158). Freitas é responsável por trazer à luz a noção de complexo de estudo. O complexo de estudo é, segundo Freitas (2009), "uma tentativa de superar o conteúdo verbalista da escola clássica, a partir do olhar do materialismo históricodialético, rompendo com a visão dicotômica entre teoria e prática" enxergando o "trabalho socialmente útil como elo ... entre teoria e prática" (p. 36). Ainda em Freitas (2009):

\begin{abstract}
A proposta é que se estude a natureza e a sociedade em conexão com o trabalho ... Cada ideia central articuladora de um complexo reúne as três dimensões, as quais, em conjunto, devem refletir a "complexidade" daquela parte da realidade escolhida para estudo - a sua dialética e sua atualidade, vale dizer, suas contradições e lutas - seu desenvolvimento enquanto natureza e enquanto sociedade, a partir do trabalho das pessoas. (p. 35, grifos do autor).
\end{abstract}

No entanto, Freitas defende que a escola projetada por Pistrak, a centralidade no trabalho, na auto-organização e na atualidade não implicam necessariamente em uma relativização ou diminuição da importância do conteúdo escolar, da aprendizagem das disciplinas. Sem perder 
de vista esta perspectiva, incluímos o desafio das Licenciaturas em Educação do Campo tratar as disciplinas em áreas do conhecimento. O que por um lado pode significar uma ótima oportunidade de superar a fragmentação curricular e um ambiente propício a restabelecer a conexão entre teoria e prática, também pode resultar em um esvaziamento gradativo de conteúdo na formação destes novos educadores. Um agravante foi possível levantar durante pesquisa com a LECAMPO (Romanini Netto, 2015), qual seja, os educandos matriculados possuem deficiência em uma ou mais disciplinas de que trata a área de conhecimento da Licenciatura. Nos prenderemos neste assunto adiante.

\section{Uma nova ciência para um novo sujeito}

Um novo desafio está contido no movimento real das Licenciaturas em Educação do Campo: a formação por área do conhecimento. Caldart (2010) nos contextualiza que existia uma intencionalidade na luta pelas licenciaturas e que um curso nos moldes das licenciaturas disciplinares foi descartada. Em primeiro lugar, porque as escolas do campo invariavelmente não conseguem manter um professor por disciplina em escolas que contém pequena quantidade de estudantes, ou a localização é um dificultador. Um outro motivo seria que, as licenciaturas disciplinares dificilmente abarcariam as mudanças necessárias, assim como, não faz parte da ideia original da Educação do Campo privilegiar uma Geografia do campo ou uma Física do campo. Ainda, a autora nos recorda que o trabalho por área, além de ser um motivador ao trabalho docente em equipe, pode ser um bom pretexto para rediscussão da forma de organização curricular das escolas do campo. A conquista se deu a partir da Resolução CNE/CEB No 2, de 30 de janeiro 2012 que define Diretrizes Curriculares Nacionais para o Ensino Médio, onde ampara legalmente a área do conhecimento organizada em: a) Linguagens; b) Matemática; c) Ciências da Natureza; d) Ciências Humanas. (Resolução n. 2, 2012).

Ainda, Caldart (2010) nos alerta para contradição expressa pela docência por área. A área do conhecimento ganhou uma centralidade maior do que teve nos debates iniciais sobre as licenciaturas, suprimindo, por vezes, os debates sobre prática e teoria e a especificidade do campo. A autora, no entanto, vê esta movimentação indicar potencialidades importantes, onde é posto a forma curricular disciplinar em questão.

A reboque do debate sobre a docência por área do conhecimento surge a 
interdisciplinaridade como opção ao tratamento dos conteúdos escolares. Para Rodrigues (2010), a interdisciplinaridade é proposta como possibilidade de superação dos limites apresentados pelas ciências na explicação dos fenômenos ocorridos, em especial na segunda metade do século XX, em duas linhas principais de argumentação: a primeira está relacionada à complexidade dos problemas enfrentados atualmente pela sociedade; a segunda baseia-se no questionamento aos limites da organização do conhecimento, numa perspectiva de unificação do saber. Citando Fazenda, Rodrigues alerta que o termo interdisciplinaridade não apresenta um sentido único e estável, tratando-se de um neologismo cuja significação nem sempre é a mesma e cujo papel nem sempre é compreendido da mesma forma (Fazenda, 2002 apud Rodrigues, 2010, p. 107).

Se a interdisciplinaridade está, em linhas gerais, preocupada no entrelaçamento entre as disciplinas científicas, cabe a nós questionar como se deu a fragmentação do conhecimento? Para Santomé (1998 apud Rodrigues, 2010), o processo de industrialização promovido pelo modelo econômico e capitalista, principalmente ocorrido a partir do século XIX, é um dos momentos principais aberturas para o parcelamento e ruptura do conhecimento em disciplinas. Contudo, a industrialização não teria acontecido sem a Revolução Científica durante o período Iluminista, onde teve seu desenvolvimento muito influenciado por pensadores como Galileu, Descartes, Bacon, Keppler, Copérnico, Newton, entre outros, a partir do século XVI.

No que diz respeito à Filosofia da Ciência, Francis Bacon, fundador do empirismo britânico, foi fundamental para a perspectiva de domínio sobre a natureza e desmistificação sobre o desconhecido, assim como Isaac Newton foi decisivo para a compreensão mecanicista e matematizadas da natureza. Esta gama de pensadores trouxeram a razão e a racionalidade à luz, “iluminaram” a sociedade imersa em uma escuridão que durou séculos. Em síntese, o período Iluminista deixou um legado sem precedentes na história e deu as bases para o desenvolvimento científico e para a revolução social que ocorreria no fim do século XVIII. Entendemos também, que sem uma postura crítica em ao idealismo religioso e às relações de poder durante o modo de produção feudal, o Iluminismo não teria sido uma corrente do pensamento revolucionária. Ou seja, o desenvolvimento técnico e científico não está descolado das forças produtivas e das relações de produção de cada período histórico. 
Esta questão é central para a Sociologia do Conhecimento, qual seja, os usos sociais das ideias, ideologias e epistemologias. Tão importante para esta disciplina, quanto o conhecimento, é a dicotomia entre o falso e o verdadeiro, em especial, na objetividade científica.

Dando continuidade, a partir desta nova perspectiva, Löwy (1987) entende que as doutrinas do direito natural e de uma ciência natural da sociedade, ascendentes no século XVIII, possuíam uma dimensão utópico-revolucionária, críticas à ordem feudal-absolutista. Condorcet teria sido quem contribuiria de maneira mais direta à gênese desta nova corrente. Sua proximidade, em particular com Adam Smith, o levou a pensar a Economia Política poder ser submetida à precisão do cálculo e ao método das Ciências da Natureza. Segundo o autor, em Condorcet havia um objetivo confesso de separar o conhecimento social dos interesses e paixões dominantes, em um sentido de luta contra as doutrinas teológicas. Tratava-se de se apoiar no método de Bacon e Descartes e transferilos às ciências econômicas e políticas. Essa seria uma herança fundamental da filosofia iluminista ao positivismo, a saber, a neutralidade da ciência. Löwy esclarece que não foi Condorcet quem fundou a filosofia positivista, mas sim seu sucessor
Augusto Comte. O método positivo, já colhendo os frutos da Revolução Francesa, procurava em sua gestação afastar a ameaça que apresentavam as ideias negativas, críticas, e subversivas da filosofia do Iluminismo e do socialismo utópico. Comte determina o conceito de física social, a ciência que "tem por objeto o estudo dos fenômenos sociais considerados dentro do mesmo espírito que os fenômenos astronômicos, físicos, químicos e fisiológicos, quer dizer, como sujeitos a leis naturais invariáveis, cuja descoberta é o objetivo específico de suas pesquisas" (Löwy, 1987).

Emile Durkheim foi quem deu seguimento à neutralidade do pensamento científico característico da filosofia positivista. Diferentemente de Comte, Durkheim não estava em comum acordo com o conceito de física social, e dedicou sua carreira acadêmica na constituição das bases da nova ciência social, a Sociologia. Além de seus trabalhos filosóficos e sociológicos, Durkheim contribuiu diretamente no estabelecimento do liberalismo francês na época da terceira república. Perspectivas estas que foram aprofundadas no século XX sob influência do Taylorismo e do Fordismo. A partir destas condições passamos a encontrar a aliança frutífera entre a produção científica, cada vez mais específica e 
fragmentada, e o industrialismo, em um objetivo uno: o lucro dos empresários.

De uma forma ou de outra, ainda hoje o empirismo mecanicista e o positivismo ainda são epistemologias majoritárias na produção do conhecimento científico, principalmente nas Ciências Naturais, da Terra e Agrárias, salvo exceções dentro das Ciências Humanas e Sociais e de novas epistemologias contemporâneas, por exemplo, às sob influência da Ecologia. Em síntese, para a Sociologia do Conhecimento, o empirismo mecanicista e o positivismo reconhecem o conhecimento de forma neutra, sem julgamento de valor, a-histórico, possíveis de serem comprovados segundo leis gerais.

Contudo, o positivismo não se estabeleceu sem críticas. As correntes que mais conquistaram adeptos foram $\mathrm{O}$ historicismo e o marxismo. Segundo Löwy (1987), o historicismo é a corrente que dominou o pensamento alemão durante um século, da qual a Sociologia do Conhecimento é herdeira. Em linhas gerais, para o historicismo: a) todo fenômeno cultural, social ou político é histórico e não pode ser compreendido senão através da e na sua história; b) existem diferenças fundamentais entre os fatos naturais e históricos; c) não somente o objeto da pesquisa está imerso no fluxo da história, como também o sujeito objetivante, seu método, seu ponto de vista (Löwy, 1987, pp. 63-64). Ainda sim, o historicismo é, em sua origem, uma corrente em geral conservadora, e às vezes reacionária, principalmente em relação à filosofia Iluminista e à Revolução Francesa. Contudo, Karl Manheim, influenciado pelo livro História $e$ consciência de classe (1923) de Lukács, traria uma concepção original ao historicismo. A virada de Manheim compreende o conjunto da estrutura da consciência dependente ou vinculada a uma posição social. Em outras palavras, para Manheim, todo pensamento ou conhecimento é dependente de uma perspectiva social e historicamente condicionada, e ligada a um ponto de vista social inevitavelmente parcial e tendencioso. Löwy enfatiza que, para Manheim, esta perspectiva social não é somente fonte de erro. Ela é também fonte de lucidez e de conhecimento verdadeiro, ela abre o acesso a certos domínios da realidade, esclarece certos aspectos do ser social. Manheim adentra no cerne da epistemologia marxista/lukacsiana ao levantar a questão: qual é a classe social cujo ponto de vista permite o máximo de conhecimento possível em uma época determinada?

Para Marx e alguns marxistas, no período de domínio do modo de produção 
capitalista, essa classe é a unidade camponesa e operária, a classe trabalhadora. No entanto, esta perspectiva não é unívoca no marxismo. Apesar de o marxismo ser considerado a primeira corrente a "desmascarar" as ideologias de classe por detrás da neutralidade axiológica do positivismo, foi também profundamente afetado por esta perspectiva. Löwy (1987) ressalta principalmente o período da Segunda Internacional, fim do século XIX e início do século $\mathrm{XX}$, onde houve um forte exercício de retirar as paixões e o romantismo socialista, em prol de uma teoria científica objetiva. Em um recorte à obra de Enrico Ferri, Socialismo e ciência positiva: Darwin-Spencer-Marx (1894), Löwy entende que para o italiano "o socialismo é uma fase de evolução humana natural e espontânea, portanto inevitável e irrevogável" onde "não existe necessidade de revolução no sentido habitual e inexato de revolta violenta e tumultuada" (Löwy, 1987, p. 112).

Outro fenômeno, digno de nota interior ao marxismo, é o que Löwy (1984) coloca como ideologia estalinista. Para o autor, o estalinismo se tornou uma camada social burocrática da União Soviética, derivada do movimento operário russo, mas que não se estruturava em classe no sentido marxista do termo. Para se manter no poder o estalinismo deveria apresentar seu ponto de vista como sendo o do proletariado, resultando no que o autor chama de ocultação ideológica. Mais que isso, o período estalinista foi duramente repressivo aos seus opositores, demonstrando seu lado mais conservador. Aqui, Löwy chama atenção para um fenômeno novo: a tentativa de ideologização das Ciências Naturais. Esta inovação se baseia na ideia de que as ciências naturais teriam um caráter "burguês", o que o autor chama de positivismo ao inverso, ou seja, "enquanto o positivismo quer 'naturalizar' as ciências sociais e políticas, o estalinismo pretende 'politizar' as Ciências da Natureza; os dois têm em comum a incompreensão da especificidade das ciências humanas e de sua distinção metodológica com relação às ciências naturais" (Löwy, 1987, p. 161). A vitória principal se deu na assunção de Lyssenko à Academia Lenin de Ciências Agrícolas, em 1948, impondo o lyssenkismo como doutrina científica.

Desde a Sociologia do Conhecimento, Löwy concorda que, produto deste debate, importa-nos a compreensão de que as condições sociais e políticas determinam a orientação da pesquisa científica e a aplicação de seus resultados, sejam elas ciências sociais ou naturais. Por isso, assim como em Caldart (2010) e Rodrigues (2010), entendemos 
que a interdisciplinaridade não pode ser tomada como a solução da fragmentação científica em si. Os materiais que estamos revisando sobre a Educação do Campo chamam a atenção para utilização de categorias do método materialista histórico-dialético, como a totalidade, o trabalho e a luta de classes, serem capazes de formar um novo sujeito, consciente de seu papel na construção de uma nova sociedade. Isto se daria porque a epistemologia marxista se preocupa em restaurar a relação dialética entre sujeitoobjeto, tanto da produção científica quanto da prática docente (Rolo, 2015, p. 152). Em outras palavras, significa exercitar a superação da neutralidade imposta pela filosofia positivista hegemônico nestes dois campos, ciência e educação.

No nosso entendimento, o materialismo histórico-dialético possui diversos representantes que utilizam o método para compreensão da realidade social, os quais produzem referência teórica aos partidos políticos, movimentos sociais, centrais sindicais, revistas acadêmicas, entre outros. No entanto, a aplicação do método para compreensão da realidade natural é um momento tenso, sujeita à crítica tanto de intelectuais divergentes ao marxismo, quanto de marxistas como Löwy. Mais que isso, a própria conexão entre as Ciências
Humanas e Sociais e as Ciências Naturais e da Terra é muito polêmica, ainda que existam adeptos. Segundo Foster (2005), Marx era um deles e uma revisão sobre seu materialismo desvelaria a questão da unidade entre as ciências. Seguiremos a partir desta questão.

\section{Ciências da Natureza e materialismo, do século XIX aos dias de hoje}

Desde a Antiguidade o desconhecimento sobre as causas dos fenômenos naturais foram, e ainda podem ser, interpretados de forma mística, mitológica e até teística. A disseminação do conhecimento iluminista mudou gradativamente este quadro. No entanto, a época Iluminista não foi a primeira. Segundo a apurada historiografia de Foster (2005), o grupo de atomistas gregos Leucipo, Demócrito, Empédocles e, posteriormente, Epicuro, teriam, em suas obras filosóficas, adiantado algumas das ideias fundamentais determinadas pelos iluministas. Contudo, estes materiais foram considerados, na Idade Média, heresias, apologias ao ateísmo, em relação aos materiais produzidos por Aristóteles e Platão. O atomismo grego e filosofia de Epicuro teriam influenciado profundamente o Iluminismo inglês e francês, na sua luta contra a filosofia aristotélica do cristianismo. A título de 
exemplo Hariot, Hobbes, Boyle, Newton e

Bacon teriam estudado sistematicamente os gregos. Marx também foi profundamente influenciado por Epicuro, tornando-o tema de sua tese de doutoramento. Foster (2005, p.84) afirma Marx ter enxergado em Epicuro "o primeiro a captar a aparência como aparência, isto é, como alienação da essência”.

Ainda assim, o jovem Marx precisava desenvolver uma ruptura mais clara com o sistema hegeliano, o qual interpretava o desenvolvimento da história como reflexo do desenvolvimento da mente. E o fez, em grande medida, através do materialismo de Feuerbach. Apesar de Hegel ter sido o primeiro a avançar na noção da alienação do trabalho humano, Marx o teria considerado "incapaz de perceber a auto-alienação da atividade prática humana como base da alienação das pessoas, não só de si mesmas, mas também da sua existência real, sensorial: da sua relação com a natureza" (Foster, 2005, p. 108). Assim, em Marx a solução para alienação dos seres humanos em relação à natureza somente seria descoberta no reino da prática, na história humana (Foster, 2005, p. 115). Ao tecer uma análise crítica à filosofia alemã sobre a apropriação da atividade humana, Marx
\& Engels esclarecem seu materialismo onde:

... não se parte daquilo que os homens dizem, imaginam ou representam, tampouco dos homens pensados, imaginados e representados para, a partir daí, chegar aos homens de carne e osso; parte-se dos homens realmente ativos e, a partir de seu processo de vida real, expõe-se também o desenvolvimento dos reflexos ideológicos e dos ecos desse processo de vida. Não é a consciência que determina a vida, mas a vida que determina a consciência. (Marx \& Engels, 2007, p. 94).

No entanto, o desenvolvimento do método de Marx e Engels precisaria também ter uma ruptura com o materialismo naturalista de Feuerbach, isto porque lhe faltaria em seu materialismo uma concepção madura de história e agência humana prática.

Feuerbach fala especialmente do ponto de vista da ciência natural; ele menciona segredos que só se mostram aos olhos do físico e do químico; mas onde estaria a ciência natural sem a indústria e o comércio? Mesmo essa ciência natural "pura" obtém tanto sua finalidade como seu material apenas por meio do comércio e da indústria, por meio da atividade sensível dos homens. (Marx \& Engels, 2007, p. 31).

O materialismo histórico de Marx e Engels, para Foster, teria sido uma resposta tanto à Feuerbach quanto à Teologia Natural, em especial Malthus. As evidências das teorias Iluministas 
alcançaram grandes pensadores que, ao invés de repudiar as novas ideias, se debruçaram sobre a capacidade da ciência provar a existência de Deus, e estes o fariam através do estudo da natureza. O esforço destes pensadores não foi resumido ao campo da Ciência Natural, mas também em seu flerte com a Economia Política em sua forma mais conservadora. Segundo Foster (2005), o Ensaio sobre a população de Malthus, de 1798, visava demonstrar que o princípio da população² era um obstáculo à própria realização de uma sociedade mais igualitária. Já Marx divergia radicalmente a esta concepção estática da natureza humana:

As ciências naturais desenvolveram uma enorme atividade e se apropriaram de um material sempre crescente. Entretanto, a filosofia permaneceu para elas tão estranha justamente quanto elas permaneceram estranhas para a filosofia. A fusão momentânea foi apenas uma ilusão fantástica ... quanto mais a ciência natural interveio de modo prático na vida humana mediante a indústria, reconfigurou-a e preparou a emancipação humana, tanto mais teve de completar, de maneira imediata, a desumanização. A indústria é a relação histórica efetiva da natureza e, portanto, da ciência natural com o homem; por isso, se ela é apreendida como revelação exotérica das forças essenciais humanas, então também a essência humana da natureza ou a essência natural do homem é compreendida dessa forma, e por isso a ciência natural perde a sua orientação abstratamente material, ou antes idealista, tornando-se a base da ciência humana, como agora já se tornou - ainda que em figura estranhada - a base da vida efetivamente humana. (Marx, 2004, p. 112, grifos originais).

Engels, exímio estudioso das transformações na ciência e na indústria, também foi crítico à postura positivista de interpretação da natureza e em $A$ dialética da natureza não perde de vista o ponto de vista histórico. Para ele:

A ciência natural, tão revolucionária a princípio, defrontou-se, de repente, com uma Natureza absolutamente conservadora, em que tudo era hoje da mesma forma que havia sido a princípio e na qual tudo teria que permanecer tal com era, até o fim do mundo ou por toda a eternidade (Engels, 1979, p. 18).

$\mathrm{Na}$ análise de Foster teria sido em oposição ao malthusianismo que a noção de proletariado surgiu com clareza dentro do marxismo. Para Engels, "Malthus estava certo a seu modo, ao afirmar que há gente demais no mundo. Ele só está errado quando afirma que há mais gente disponível do que pode ser mantida pelos meios de subsistência disponíveis.”. Então, o que explicaria os baixos salários e a pobreza não era a superpopulação em relação à oferta de alimentos, mas a superpopulação em relação à oferta de emprego, em outras palavras, a formação do "exército reserva de trabalhadores 
desempregados”. Contudo, os trabalhadores "convenceram-se de que eles, com as mãos cheias, são necessários e os capitalistas ricos, que não fazem nada ... são a população excedente" (Engels, 1984 apud Foster, 2005, p. 158).

Foster traz à luz um tema polêmico e caro, como o é para Löwy (1987), a relação da teoria da evolução de Charles Darwin e a perspectiva materialista de natureza. Polêmico, principalmente porque a fusão entre as descobertas darwinistas e as Ciências Humanas e Sociais representaram aspectos conservadores e reacionário, desde Malthus até o desenvolvimento do nacional-socialismo, nazismo e fascismo. Contudo, Marx e Engels, contemporâneos de Darwin, absorveram as novas descobertas, inclusive com otimismo, o que os dois alemães encaravam como o "grande golpe" contra as concepções teológicas do mundo, mesmo que Darwin não tivesse perdido a influência do naturalismo clerical. Em defesa às críticas de Eugen Duhring, Engels coloca:

Por maior que tenha sido o equívoco cometido por Darwin ao aceitar tão ingênua e acriticamente a teoria de Malthus, qualquer pessoa percebe à primeira vista que não se precisa de nenhum óculos malthusiano para verificar a luta pela existência na natureza ... assim como a lei do salário permaneceu válida mesmo muito depois de terem desaparecido os argumentos malthusianos nos quais Ricardo a baseou, assim a luta pela existência na natureza pode ter lugar à parte de qualquer interpretação malthusiana (Engels, 2015, p. 100).

Foster acredita que o materialismo evolucionista de Darwin é central para compreensão do desenvolvimento do materialismo histórico-dialético e para a compreensão de natureza que deriva de Marx e Engels. O que se torna evidente em um trecho de $O$ Capital:

Antes de tudo, o trabalho é um processo entre o homem e a Natureza, um processo em que o homem, por sua própria ação, media, regula e controla seu metabolismo com a Natureza. Ele mesmo se defronta com a matéria natural como uma força natural. Ele põe em movimento as forças naturais pertencentes a sua corporalidade, braços e pernas, cabeça e mão, a fim de apropriar-se da matéria natural numa forma útil para sua própria vida ... Do mesmo modo como a terra é sua despensa original, é ela seu arsenal original de meios de trabalho. Fornece-lhe, por exemplo, a pedra que ele lança, com que raspa, prensa, corta etc. ... O uso e a criação de meios de trabalho, embora existam em germe em certas espécies de animais, caracterizam o processo de trabalho especificamente humano. A mesma importância que a estrutura de ossos fósseis tem para o conhecimento da organização de espécies de animais desaparecidas, os restos dos meios de trabalho têm para a apreciação de formações socioeconômicas desaparecidas (Marx, 1983, pp. 149-151). 
A interpretação de Foster é que Marx formulava sua teoria geral do papel do trabalho, ligada à Darwin, oferecendo uma base histórico-natural. Já nos Manuscritos Econômicos Filosóficos aparece essa disposição, onde "toda a assim denominada história mundial nada mais é do que o engendramento do homem mediante o trabalho humano, enquanto o vir a ser da natureza para o homem." (Marx, 2004, p. 114, grifos do autor).

O texto de Engels Sobre o papel do trabalho na transformação do macaco em homem, segundo Foster (2005), considerado pelos biologistas evolucionistas fundador do conjunto complexo "co-evolução gene-cultura" apresenta grandes pistas da influência de Darwin:

...a mão humana tinha sido libertada [das atividades de locomoção] e poderia, sem cessar, ir adquirindo novas habilidades, sendo que a maior delas, assim conseguida, podia ser herdada e melhorada, de geração em geração. Dessa maneira, a mão não é apenas o órgão do trabalho: é também um produto deste. Somente pelo trabalho, por sua adaptação a manipulações sempre novas, pela herança do aperfeiçoamento especial assim adquirido, dos músculos e tendões (e, em intervalos mais longos, dos ossos; e, pela aplicação sempre renovada, desse refinamento herdado, à, novas e cada vez mais, complicadas manipulações), a mão humana alcançou esse alto grau de perfeição por meio do qual lhe foi possível realizar a magia dos quadros de Rafael, das estátuas de
Thorwaldsen, da música de Paganini. (Engels, 1979, p. 216-217, grifos do autor).

Outro elemento que consolidou o lugar da natureza no método materialista histórico-dialético foi o desenvolvimento da ciência moderna do solo e as descobertas de Liebig. Segundo Foster (2005), os estudos de Marx sobre renda diferencial fundiária e o estudo sistemático das obras de Liebig fortaleceram a concepção de relação homem-natureza como um metabolismo, onde, no período de expansão capitalista, há uma falha irreparável neste metabolismo. Em outro trecho de $O$ Capital:

Com a preponderância sempre
crescente da população urbana que
amontoa em grandes centros, a
produção capitalista acumula, por um
lado, a força motriz histórica da
sociedade, mas perturba, por outro
lado, o metabolismo entre homem e
terra, isto é, o retorno dos
componentes da terra consumidos
pelo homem, sob forma de alimentos
e vestuário,à terra, portanto, a eterna
condição natural de fertilidade
permanente do solo. Com isso, ela
destrói simultaneamente a saúde
física dos trabalhadores urbanos e a
vida espiritual dos trabalhadores
rurais. (Marx, 1984, p. 102).

Portanto, a crítica sobre a separação do homem com a natureza não é somente epistemológica, mas é prática, e paira sobre a primeira grande divisão do trabalho, a divisão entre cidade e campo. 
Sendo assim, a supressão do antagonismo entre cidade e campo não só é possível: ela se tornou uma necessidade direta da própria produção industrial, assim como também se tornou uma necessidade da produção agrícola e, ademais, do cuidado com a saúde pública. Somente com a fusão de cidade e campo poderá ser eliminado o atual envenenamento do ar, da água e do solo, somente com ela as massas que atualmente definham nas cidades poderão ter seu excremento utilizado para geração de plantas, em vez de para a geração de doenças. (Engels, 2015, p. 330).

Esta revisão sobre 0 desenvolvimento do materialismo e natureza do século XIX tem a intencionalidade de melhor basear um dos seus argumentos principais de Foster (2005): o trajeto filosófico de Marx e Engels, em especial o materialismo, foi, em muitos adeptos do marxismo, abandonado em detrimento às categorias sínteses e à prática política revolucionária, sucumbindo com frequência ao positivismo e ao mecanicismo. O ponto crucial seria a concepção de história natural que deriva da análise de Darwin e que permite um entendimento co-evolutivo e dialético da natureza. E foi isto que se tornou a chave do entendimento da relação entre a concepção materialista de natureza e a concepção materialista de história. Poucos autores deram continuidade à tais concepções desde Engels. A primeira metade do século XX, Foster dá ênfase aos russos Bukharin, e aos pais da ecologia soviética Vernadsky e Vavilov, antes destes serem afetados pela ascensão de Lyssenko e perseguidos como traidores da revolução no período estalinista. A Inglaterra também teria concentrado pensadores originais como Caudwell, Bernal, Haldane, Needham. Na segunda metade do século XX é digno de nota The dialetical biologist (1985) de Levin e Lewotin, professores de Harvard, entre outros.

Contudo, estas não são as únicas perspectivas a explorar um caminho científico alternado ao empirismo positivista. Principalmente após o surgimento mais apurado das novas questões ambientais diversas correntes do pensamento surgiram a fim de explicar as consequências do desenvolvimento capitalista sobre a natureza. $\mathrm{O}$ desenvolvimento da Ecologia como ciência foi fundamental para esse processo, assim como os novos movimentos sociais de caráter ambiental, principalmente a partir da segunda metade do século XX. Anthony Giddens e Ulrich Bech foram centrais para contribuição de uma teoria social e ambiental a partir da análise de uma modernidade reflexiva, assim como, Jüger Habermas, influenciado pela teoria da ação weberiana. Desde a perspectiva da economia ecológica temos Joan Martínez 
Alier, dando continuidade ao pensamento original de Nicholas Georgescu-Roegen. A aliança da Ecologia com a Ciência Agrária também foi frutífera, como exemplo temos, Stephen Gliessman, Miguel Altieri, Eduardo Sevilla Guzmán, Víctor $\mathrm{M}$. Toledo. Novas epistemologias foram pensadas a partir de Fritjof Capra, Edgard Morin, Ilya Prigogine, Ignacy Sachs, Enrique Leff, entre outros.

Certamente muitos pensadores originais não foram relacionados nesta breve revisão, sobretudo, nos interessa afirmar que hoje há uma gama enorme de opções epistemológicas e metodológicas que tratam da relação sociedade natureza de forma articulada. Esse fator exige dos tomadores de decisão uma compreensão apurada de Filosofia e História da Ciência para adequar o método à realidade social. No que diz respeito ao campo educacional, o desafio da atualidade é trazer para as salas de aula uma concepção de natureza e de relação sociedade natureza alternada às concepções filosófico-pedagógicas dominantes e presentes nos materiais didáticos. O movimento Por uma Educação do Campo é protagonista neste aspecto, o que não impede que sua ação seja contraditória, sendo possível uma reflexão dos encontros e desencontros na formação de educadores do campo sob a perspectiva materialista histórico-dialética das Ciências da Natureza.

\section{Considerações finais}

Não temos a intenção, neste trabalho, de sermos neutros. As escolhas presentes neste artigo são resultado da experiência prática e teórica do autor com relação às temáticas apresentadas. A objetividade deste trabalho é determinada em sua relação com os grupos sociais que protagonizam a construção da temática abordada.

Levando em consideração estes elementos entendemos que o materialismo histórico-dialético é capaz de fundamentar novas análises sobre a realidade natural. Isto porque o materialismo prático, coevolutivo, permite captar a relação sociedade e natureza em um metabolismo, dialético, não estático, e por consequência fornece à cognição dos fatos concretos, sociais ou naturais, uma unidade. Isto não pode querer dizer que o método é estático. Aplicar o método a ele mesmo significa dizer que o melhor método varia de acordo com a prática social em relação com a natureza a cada tempo histórico. Tampouco queremos afirmar que, à luz do método materialista histórico-dialético, os outros métodos e metodologias são falsos. Como nos ajuda a Sociologia do 
Conhecimento a escolha do método é socialmente posicionada, sendo que, cada grupo social enfrenta contradições diferentes a se superar e escolherá o método e metodologia cabível a essa tarefa. No entanto, no que se refere à concepção original dos MSPdoC, a Educação do Campo não pode se dar ao luxo de não "enxergar" as contradições que o materialismo histórico-dialético expõe, por exemplo, sobre a agricultura industrial capitalista, a questão agrária e a luta de classes no campo. Mais que isso, nossa revisão bibliográfica reforça que o método é capaz de superar os limites gerados pelo desenvolvimento do empirismo mecanicista positivista e, ao mesmo tempo, empoderar os sujeitos oprimidos (os trabalhadores e a natureza) pelas relações de produção atual.

Entendendo o estabelecimento da Educação do Campo como um momento tenso e contraditório, cabe perguntar, quais são os encontros e desencontros presentes na formação dos educadores do campo do ponto de vista materialista históricodialético das Ciências da Natureza? Um primeiro desencontro nos salta os olhos, seja ele: a disputa de concepção, tanto de educação quanto de ciência, entre os sujeitos que interagem na execução do projeto educativo. A medida que outros atores (gestores de políticas públicas, instituições de ensino, entre outros) se incorporam na realização da Educação do Campo, a concepção originária é ameaçada em detrimento a novos processos. Neste sentido Caldart $(2008,2010)$ e Oliveira \& Gómez (2014) antecedem essa preocupação.

Outro desencontro possível está ligado aos próprios projetos políticopedagógicos dos cursos de Pedagogia e Licenciatura, onde os formatos disciplinares estão, a princípio, estruturalmente limitados a oferecer aos futuros educadores práticas capazes de transformar as futuras escolas de atuação. Ou seja, há necessidade destes novos educadores estarem munidos de ferramentas didáticas que estimulem um entendimento totalizante dos conteúdos escolares, ou como o professor Márcio Rolo (2015) coloca, é necessário que o educando (futuro educador) compreenda todas as etapas do processo científico: produção, transmissão, consumo e financiamento. $\mathrm{O}$ que nos remete a outro possível desencontro, os educadores têm pouca autonomia em relação aos conteúdos dos materiais didáticos, os quais são ditados pelo expressivo mercado educacional e editorial, e são apoiados por movimentos conservadores como o Todos Pela Educação e Escola Sem Partido, representando outra arena de combate. Em 
outras palavras, os conteúdos das Ciências da Natureza presentes nos materiais didáticos não contemplam uma perspectiva co-evolutiva, dialética ou histórico natural, o que também expõe também a fragilidade de se tomar interdisciplinaridade em si, como já mencionado anteriormente.

Existe também um desencontro sistêmico em relação à apreensão teórica do educando das Licenciaturas. Desde o projeto de Educação do Campo, há uma grande preocupação, no que se refere aos novos educadores, em se apropriarem dos conteúdos básicos da Química, Física e Biologia, de Educação, Questão Agrária, Agroecologia, e mais, que os articulem criticamente à luz do método materialista histórico-dialético. A princípio esta tarefa nos parece ser demasiado grande. Em grande medida porque, como levantamos em outra parte do texto, os educandos recém matriculados podem ter deficiência em uma ou em todas as disciplinas de que trata o curso, resultado do histórico descaso do poder público com as escolas do campo. Assim, torna-se preciso que os educadores dos Institutos de Ensino Superior estejam preparados para fomentar a articulação entre estes campos científicos, ou seja, é preciso que os educadores reconheçam a concepção originária de Educação do Campo que deriva dos MSPdoC.
Apesar das contradições sublinhadas a cima, nossa revisão bibliográfica converge para um encontro possível, o princípio educativo do trabalho. Isto porque o princípio educativo do trabalho está no cerne da epistemologia marxista no que diz respeito à educação voltada para a vida nela mesma. O que não quer dizer que o trabalho é mais importante que absorver os conteúdos escolares. Ao contrário, quer dizer que os conteúdos escolares devem ser determinados pela prática social de cada grupo social. É a partir deste aspecto, em nosso entendimento, que Caldart (2008) cobra a especificidade da Educação do Campo, pois a escola que reflete a realidade da fábrica, não será a mesma escola que reflete a realidade da agricultura, e nem por isso deixará de emancipar os filhos dos trabalhadores unidos. Neste momento, é importante expor a experiência dos Centros de Formação e Escolas dos MSPdoC na execução do Diálogo de Saberes (Guhur \& Silva, 2010), assim como dos complexos de estudos (Sapelli, Freitas \& Caldart, 2015)

O princípio educativo do trabalho pode ser também um articulador da transição a uma nova produção científica. Isto porque ainda temos que expandir a variedade de materiais teóricos das Ciências da Natureza que emanam do 
materialismo histórico-dialético. É importante ressaltar que, nem a epistemologia marxista nem o projeto de Educação do Campo negam os conhecimentos gerados pelos pensadores iluministas, pelo contrário, a apreensão destes conteúdos é determinante para o novo sujeito se reconhecer no mundo e produzir novas práticas e teorias, o diferencial é levar em conta que as teorias não podem estar descoladas da prática social. Ainda que Löwy (1987) defenda a especificidade de cada campo científico, a ousadia de desenvolver uma nova ciência sugere questionar, por exemplo, como seria pensar a lei da gravidade, sob o ângulo histórico-dialético? Certamente parece um absurdo fazer esta questão sobre uma lei que age em todos os corpos materiais do globo terrestre. A resposta é difícil de visualizar, contudo, sem dúvida, ela estará relacionada à prática social. Assim como quando recorremos à experiência da Pedagogia Socialista, podemos concluir que o momento da pesquisa exploratória deve anteceder o estudo de conteúdos (Pistrak, 2009). Assim, em um novo projeto educativo, o conhecimento sobre a fotossíntese não virá antes dos conhecimentos práticos sociais sobre as plantas, as florestas ou a agricultura. À luz deste novo projeto educativo, uma nova ciência não pode estar descolada dos problemas sociais dos grupos sociais. Cabe aqui dizer, no nosso entendimento, a epistemologia marxista não produz mais verdade do que o conhecimento popular. Resta nos perguntar: o conhecimento popular é capaz de superar a dominação do homem pelo homem e pela natureza? Sem querer dar esta resposta podemos afirmar que, sem dúvida, esta é uma questão central ao materialismo histórico-dialético.

\section{Agradecimentos}

A Brigada Chico Mendes, ao Setor Pedagógico, aos educandos e trabalhadores da Escola Latino-Americana de Agroecologia, pelo aprendizado e pela acolhida. Ao Conselho Nacional de Desenvolvimento Científico e Tecnológico (CNPq) pelo financiamento.

\section{Referências}

Arroyo, M. G. (2012). Formação de educadores do campo. In Caldart, R. S., Pereira, I. B., Alentejano, P., \& Frigotto, G. (orgs.). Dicionário da Educação do Campo (pp. 359-365). Rio de Janeiro/São Paulo: EPSJV/Expressão Popular.

Caldart, R. S. (2008). Sobre educação do campo. In Santos, C. A. (Org.). Educação do Campo: Campo-Políticas Públicas Educação (pp. 67-86). Brasília: INCRA/MDA/NEAD.

Caldart, R. S. (2010). Licenciatura em Educação do Campo e projeto formativo: 
qual o lugar da docência por área? In Caldart, R. S. (Org). Caminhos para a transformação da escola. Reflexões desde Práticas de Licenciatura em Educação do Campo (pp. 127-154). São Paulo: Expressão popular.

Engels, F. (1979). A dialética da natureza. São Paulo: Paz e Terra.

Engels, F. (2015). Anti-Dühring. São Paulo: Boitempo.

Foster, J. B. (2005). A ecologia de Marx: materialismo e natureza. Rio de Janeiro: Civilização Brasileira.

Freitas, L. C. D. (2009). A luta por uma pedagogia do meio: revisitando o conceito. In Pistrak, M. M. (Org.). A escola-comuna (pp. 9-101). São Paulo: Expressão Popular.

Freitas, L. C. D. (2010). A escola única do trabalho: explorando os caminhos de sua construção. In Caldart, R. S. (Org.). Caminhos para a transformação da escola. Reflexões desde Práticas de Licenciatura em Educação do Campo (pp. 155-175). São Paulo: Expressão popular.

Giddens, A. (1996). A modernidade sob um signo negativo: questões ecológicas e política de vida. In Giddens, A. (Org.). Para além da esquerda e da direita: o futuro da política radical (pp. 224-258). São Paulo: Ed. Unesp.

Guhur, D. M. P., \& Silva, I. M. D. S. (2010). Contribuições do diálogo de saberes à educação profissional em agroecologia no MST. In Anais do Seminário de Pesquisa do PPE (pp. 1-20). Maringá: UEM/DFE/DTP/PPE.

Instituto de Educação Josué de Castro [IEJC]. (2015). Seminário sobre ensino de Ciências da Natureza nas escolas do campo. In Caldart, R. S., Stedile, M. E., \& Daros, D. (Orgs.). Caminhos para a transformação da escola 2: Agricultura camponesa, educação politécnica e escolas do campo (pp. 73-114). São Paulo: Expressão Popular.

Kolling, E. J., Nery, I., \& Molina, M. C. (1999). Por uma educação básica do campo. Brasília: Fundação Universidade de Brasília.

Londero, R. R. (2014). A transdisciplinaridade ente os Estudos Culturais e as Ciências Agrárias e Naturais. In Silva, I. S., Souza, H., \& Ribeiro, N. B. (Orgs.). Práticas contra-hegemônicas na formação de educadores: reflexões a partir do curso de Licenciatura em Educação do Campo do sul e sudeste do Pará (pp. 191208). Brasília: NEAD.

Lopes, A. R. C. (1999). Conhecimento escolar: ciência e cotidiano. Rio de Janeiro: EdUERJ.

Löwy, M. (1987). As aventuras de Karl Marx contra o Barão de Münchhausen: marxismo e positivismo na sociologia do conhecimento. São Paulo: busca Vida.

Löwy, M. (2007). O marxismo na América Latina: uma antologia de 1909 aos dias atuais. São Paulo: Ed. Fundação Perseu Abramo.

Marx, K., \& Engels, F. (2007). A ideologia Alemã. São Paulo: Boitempo.

Marx, K. (1983). O capital: crítica da economia política. São Paulo: Abril Cultural. 1, t. 1.

Marx, K. (1984) O capital: crítica da economia política. São Paulo: Abril Cultural. 1, t. 2.

Marx, K. (2004) Manuscritos econômicofilosóficos. São Paulo: Boitempo.

Ministério do Desenvolvimento Agrário. (2004). Programa Nacional de Educação 
na Reforma Agrária PRONERA: Manual de Operações. Brasília: INCRA.

Movimento dos Trabalhadores Rurais Sem Terra. (1996). Princípios da educação no MST. Caderno de Educação, 8. São Paulo.

Movimento dos Trabalhadores Rurais Sem Terra. (1999). O que queremos com as escolas dos assentamentos. Caderno de Formação, 18. São Paulo.

Movimento dos Trabalhadores Rurais Sem Terra. (2005). Dossiê MST - Escola: Documentos e Estudos 1990-2001. Caderno de Educação, 13. Curitiba.

Moreno, G. S. (2014). Reflexões sobre a organização curricular em Ciências Agrárias e Naturais na Educação do Campo. In Silva, I. S., Souza, H., \& Ribeiro, N. B. (Orgs.). Práticas contrahegemônicas na formação de educadores: reflexões a partir do curso de Licenciatura em Educação do Campo do sul e sudeste do Pará (pp. 175-190). Brasília: NEAD.

Oliveira, M. E. B., \& Gómez, J. R. M. (2014). A educação do campo no contexto do modelo de desenvolvimento rural no Brasil: o princípio educativo do trabalho como alternativa. Revista Pegada, 15(1).

Pistrak, M. M. (2009) A escola-comuna. São Paulo: Expressão Popular

Resolução No 2, de 30 de janeiro 2012. Define Diretrizes Curriculares Nacionais para o Ensino Médio. Recuperado de http://portal.mec.gov.br/index.php?option= com_docman \&view $=$ download \&alias $=986$ 4-rceb002-12\&category_slug=janeiro2012-pdf\&Itemid=30192

Rodrigues, R. (2010). Reflexões sobre a organização curricular por área do conhecimento. In Caldart, R. S. (Org.). Caminhos para a transformação $d a$ escola: reflexões desde práticas da
Licenciatura em Educação do Campo (pp. 101-128). São Paulo: Expressão Popular.

Rolo, M. (2015). A natureza como uma relação humana uma categoria histórica. In Caldart, R. S. Stedile, M. E., \& Daros, D. (Orgs.). Caminhos para a transformação da escola: Agricultura camponesa, educação politécnica e escolas do campo (pp. 139-176). São Paulo: Expressão Popular

Romanini Netto, E. (2015). A Educação do Campo e Agroecologia à luz dos movimentos sociais populares do campo. Monografia (Especialização em Questão Agrária, Educação do Campo e Agroecologia na Amazônia). IALA Amazônico - Universidade Federal do Pará, Marabá.

Sapelli, M. L. S., Freitas, L. C., \& Caldart, R. S. (Orgs.). (2015). Caminhos para a transformação da escola 3: organização do trabalho pedagógico nas escolas do campo. Ensaios sobre complexos de estudo. São Paulo: Expressão Popular.

Saviani, D. (2007). Trabalho e educação: fundamentos ontológicos e históricos. Revista brasileira de educação, 12(34), 152-165.

\footnotetext{
1 Neste textos iremos fazer o uso livre do termo classe sociais sem nos prender a atualidade do debate.

2 O princípio da população de Malthus é produto do ensaio publicado sua primeira edição 1803 com o título Ensaio sobre o princípio da população e seus efeitos sobre o futuro aperfeiçoamento da sociedade, com observações sobre as especulações de Mr. Godwin, M. Condorcet, e outros autores. Em síntese, a tese de Malthus era que a taxa de crescimento da população geral cresceria em taxa geométrica e a capacidade de produção geral de alimentos cresceria em taxa aritmética, onde, se tornaria impossível alimentar de forma adequada toda a população, e que este princípio seria um
} 
obstáculo à própria realização de uma sociedade mais igualitária (Foster, 2005).

\section{Informações do artigo / Article Information}

Recebido em : 09/07/2017

Aprovado em: 13/09/2017

Publicado em:07/12 /2018

Received on July 09th, 2017

Accepted on September 13th, 2017

Published on December 07th, 2018

Contribuições no artigo: $O$ autor foi responsável pela escrita e revisão do conteúdo do artigo, e aprovação da versão final publicada.

Author Contributions: The author was responsible for the designing, delineating, analyzing and interpreting the data, production of the manuscript, critical revision of the content and approval of the final version published.

Conflitos de interesse: $O$ autor declarou não haver nenhum conflito de interesse referente a este artigo.

Conflict of Interest: None reported.

\section{Orcid}

Emilio Romanini Netto

iD http://orcid.org/0000-0003-4525-2095

\section{Como citar este artigo / How to cite this article}

APA

Romanini Netto, E. (2018). Ciências da Natureza e materialismo histórico-dialético: encontros e desencontros na formação de educadores do campo. Rev. Bras. Educ. Camp., 3(3), 1009-1036. DOI: http://dx.doi.org/10.20873/uft.2525-4863.2018v3n2p1009

ABNT

ROMANINI NETTO, E. Ciências da Natureza e materialismo histórico-dialético: encontros e desencontros na formação de educadores do campo. Rev. Bras. Educ. Camp., Tocantinópolis, v. 3, n. 3, set./dez., p. 1009-1036, 2018. DOI: http://dx.doi.org/10.20873/uft.25254863.2018v3n2p1009

\begin{tabular}{|l|l|l|l|l|l|l|l|}
\hline Rev. Bras. Educ. Camp. & Tocantinópolis & v. 3 & n. 3 & p. 1009-1036 & set./dez. & 2018 & ISSN: 2525-4863 \\
\hline
\end{tabular}

